\title{
Clinical study to identify causative organism in microbial keratitis, their sensitivity pattern and treatment outcome.
}

\author{
Dr. Pervez Ahemed Siddiqui, Dr. Navneet Saxena, Dr. Sarita Pandre \\ M.B.B.S, M.S (Ophthalmology) Professor N.S.C.B. Medical College, Jabalpur (M.P.) \\ M.B.B.S , M.S,(Ophthalmology) Professor And Head Of Departmen N.S.C.B. Medical College Jabalpur \\ M.B.B.S ,M.S. ( Ophthalmology) $3^{\text {rd }}$ Year Resident P.G.
}

\begin{abstract}
:
Purpose - to determine epidemiological characteristic, predisposing factor, microbiological pattern, and sensitivity pattern and treatment outcome of microbial keratitis.

METHOD- The present study was conducted in 100 cases. the patient were analyzed in accordance with demographic profile, predisposing factor, microbiological status of patient in reference to $10 \% \mathrm{KOH}$, gram's stain, culture sensitivity and treatment advised in accordance with the diagnosis of the patient.

RESULT-During analysis following data were deduced, 52\%, 36\%, 9\% and 3\% had bacterial, fungal, viral and mixed flora respectively It was noted that patients involved in agriculture activity or those suffering from trauma inflicted with vegetative material had more risk of developing microbial keratitis that is $44 \%$.Overall culture was positive in $12 \%$ of bacterial and mixed infection whereas only $6 \%$ of fungal keratitis clinically diagnosed, had culture positivity, whereas viral keratitis was diagnosed clinically only, who showed adequate responses to antiviral treatment. In bacterial keratitis surgical intervention was required in $7.69 \%, B C L$ in $9.6 \%$, Perforation occurs in $19.2 \%$, whereas it healed in $59.61 \%$ and conjunctival hooding in $3.8 \%$. In fungal keratitis $27.77 \%, 13.8 \%, 41.6 \%$ and $36.11 \%$ respectively and in viral keratitis $11.11 \%$ require surgery, $55.55 \%$ healed, BCL in $11.11 \%, 22 \%$ pthisical in viral.

CONCLUSION - Study shows bacterial keratitis is more common than fungal \& viral with male predominance in younger age trauma by vegetative material or injury is most common risk factor, final diagnosis based on risk factor, clinical feature, response to treatment .Viral keratitis diagnosed clinically. Bacterial keratitis has better prognosis than fungal and viral.
\end{abstract}

Key words: microbial keratitis, microbiological sensitivity pattern and treatment outcome

\section{Introduction}

Microbial keratitis is one of the leading cause of avoidable blindness in developing nations surveys in many parts of worlds have revealed that corneal scarring is an important cause of blindness and visual impairment ( upadhyaya et al 1991; shrinivasan et al 1997;norina et al 2008; whitcher et al 1997; chirambo et al 1986).blindness survey in Nepal (brilliant et al,1985)too showed that corneal trauma and ulceration are second leading cause of unilateral blindness after cataract and are responsible for $7.9 \%$ of all blindness.

The incidence of microbial keratitis varies from place to place from USA has an incidence of 11 per 100,000 persons for microbial keratitis as compared to 799 per 100,000 persons in Nepal(upadhyaya et al 2001).epidemiological features and causative organisms for keratitis varies from region to region within the same country.

The clinical diagnosis of microbial keratitis often relies on a thourugh specific history of infectious exposure, epiological treands and morphological feature(upadhyaya et al 2001).furthermore, the course of the disease and patient management is directly affected by the lack of proper diagnosis and initiation of appropiate antimicrobial treatment. To begin the proper management required quick and accurate identification of causative microorganisms. Therefore, the evaluation of the etiological diagnosis region wise and sensitivity pattern of isolated microorganisms provide the valuable information for initiation of their management. For this, some studies in Indian subcontinent have provided the important data so this study was conducted in conducted in UPGRADED DEPATMENT OF OPHTHALOMOLOGY, N.S.C.B. medical college and hospital, Jabalpur (M.P.).

Most of the studies about microbial keratitis have primarily evaluated epidemiological features, predisposing Factors and clinical features of corneal ulceration (Whitcher et al, 1997; Srinivasan et al, 1997; Norina et al, 2008; Upadhyaya et al, 1991; Williams et al, 1987), but this study, along with the epidemiological pattern and identification of causative microorganisms, tried to include the sensitivity pattern of bacterial isolates, treatment modalities and their outcome. (Dhakhwa et al Nepal 2012 ;). 


\section{Materials and methods}

The present study was conducted in 100 cases in UPGRADED DEPATMENT OF OPHTHALOMOLOGY, N.S.C.B. medical college and hospital, Jabalpur ( M.P.) from august 2012 to august 2013 were included in the study.. the patient were analyzed in accordance with demographic profile, predisposing factor, microbiological status of patient in reference to $10 \% \mathrm{KOH}$, gram's stain , culture sensitivity and treatment advised in accordance with the diagnosis of the patient. Patients were seen consecutively after the initial clinical diagnosis of corneal ulceration was made. Ulceration was defined as a loss of the corneal epithelium with underlying stromal infiltration and suppuration associated with signs of inflammation with or without hypopyon. Typical healing ulcers were excluded, as were Mooren's ulcers, marginal keratitis, interstitial keratitis, sterile neuro-trophic ulcers and any Ulcers associated with autoimmune conditions.

Statistics: All case report forms were checked for completeness and inappropriate or illogical responses. The forms were entered using Microsoft 2007 Excel worksheet. The databases were validated and all inconsistencies and differences were resolved. Statistical analyses were performed using STATA 12 for Windows (StataCorp LP, Texas, USA). Categorical data are presented as frequency counts (percent) and compared using the chisquare or Fisher's exact statistic as appropriate. Odds Ratio and 95\% Confidence Intervals were also presented for $2 \times 2$ contingency tables. The significance level was considered Alpha $=0.05$ and at $95 \%$ confidence level.

\section{Clinical procedure}

Every patient was examined on the slit-lamp biomicroscope. The size of the epithelial defect after staining with fluorescein was measured with the variable slit on the slit-lamp and recorded in millimeters on a standardized form. The presence or absence of a hypopyon was recorded; and the height of the hypopyon was measured in millimeters. Associated ocular conditions such as blepharitis, dacryocystitis, dry eyes, corneal anesthesia, lagophthalmos, any surgery on the cornea, use of contact lens, or ocular leprosy were noted. The use of topical medication including topical corticosteroids was also noted. After a detailed ocular examination, corneal scrapings were performed under aseptic conditions on each ulcer by ophthalmologist using a flame sterilized Kimura spatula. Scrapings were performed in the slit lamp after instillation of $4 \%$ lignocaine (lidocaine). Material was obtained from scraping, the leading edge and the base of each ulcer, was inoculated directly onto Blood agar, and Sabaraud-Dextrose agar (SDA). Material from the corneal scraping was also taken on two separate glass slides for smear: one for Gram stain and the other for microscopic examination in the clinic as a $\mathrm{KOH}$ wet mount. All $\mathrm{KOH}$ smears were then sent to the laboratory for confirmation.

\section{Laboratory procedure}

All bacterial cultures were incubated aerobically at $37^{\circ} \mathrm{C}$. Cultures on blood agar were evaluated at 24 hours and then discarded if there was no growth. Fungal cultures inoculated onto SDA were incubated at $27^{\circ} \mathrm{C}$, examined daily, and discarded after 2 weeks if no growth was present in culture. Microbial cultures were considered positive only if growth of the same organism was demonstrated on two or more solid media; or there was semi confluent growth at the site of inoculation on one solid medium associated with the identification of the organism of appropriate morphology and staining characteristics on Gram stain or $\mathrm{KOH}$ mounted corneal smears. The specific identification of bacterial pathogens was based on microscopic morphology, staining characteristics, and biochemical properties using standard laboratory criteria. Fungi were identified by their colony characteristics on SDA. All culture positive samples were tested for their sensitivity pattern with commonly available/ used antimicrobials. Treatment decision was based on clinical judgment and response to empirical treatment. Culture $\&$ sensitivity pattern was taken into account after 48 hours when culture sensitivity report was available of bacterial growth.

Incidence of keratitis

\section{Results}

In this study out of 100 cases, $52 \%$ are bacterial keratitis, $36 \%$ are fungal , $9 \%$ viral and $3 \%$ are mixed (Fig. 1). 


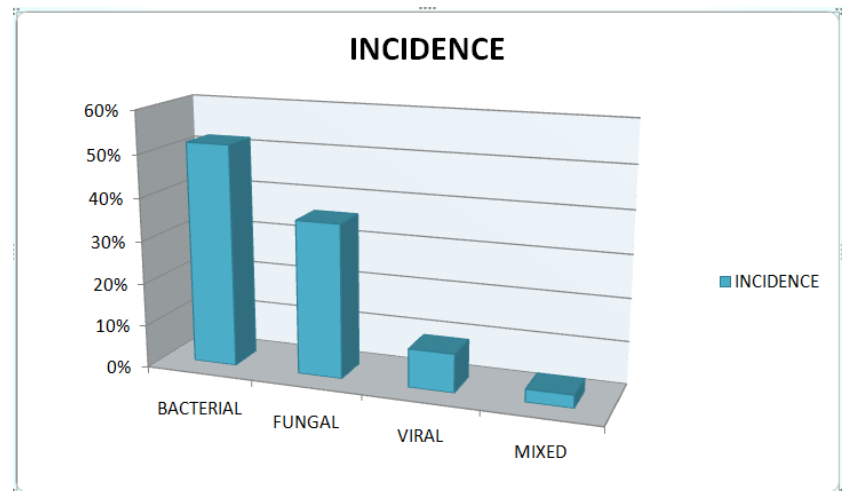

Fig 1: Incidence various keratitis in 100 cases .

Epidemiological characteristics

100 cases with the clinical diagnosis of corneal ulcers were enrolled in this study 69 cases were males and 31 were females. Ulceration occurred most frequently in the age group of 30-39 years in 38 cases, followed by 28 cases in the age group of less than 30 years. (Fig. 2).

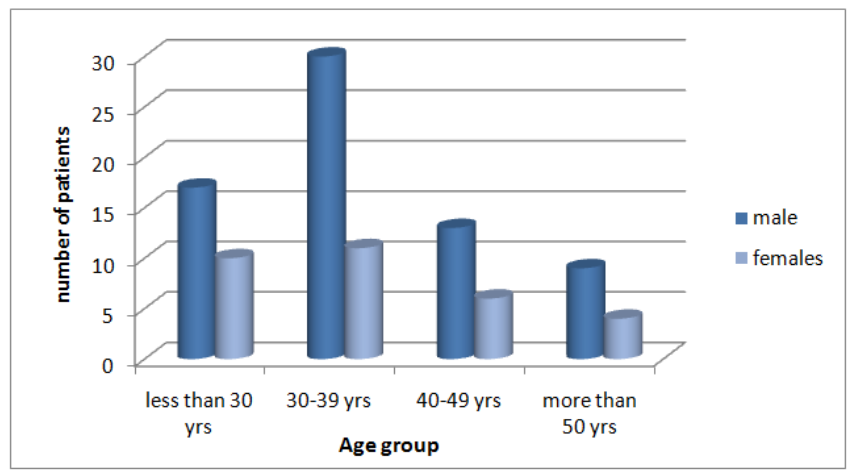

Fig 2: Age and sex distribution of 100 patients with corneal ulceration

\section{Predisposing factors/ risk factors}

Patients with history of trauma or injury by vegetative material are at more risk for development of corneal ulcer than other risk factors. (table.1).

TABLE 1

\section{PREDISPOSING/RISK FACTORS FOR KERATITIS}

\begin{tabular}{|l|l|l|}
\hline S.No. & Risk factors & \% at risk \\
\hline 1 & Acute conjunctivitis & 26 \\
\hline 2 & Trauma & 44 \\
\hline 3 & Dacriocystitis & 16 \\
\hline 4 & No past history & 9 \\
\hline 5 & undetermined & 5 \\
\hline Total & & 100 \\
\hline
\end{tabular}

Table1: predisposing/risk factors distribution of 100 patients for development of corneal ulceration

\section{Microbial diagnosis}

Cultures were positive and fulfilled the criteria established for the presence of infection. shows $12 \%$ cultures, exhibited pure bacterial growth, although $3 \%$ cultures were mixed type. Pure fungal growth was present in $6 \%$ all cases of corneal ulcers (table. 2 ) 
TABLE 2

Microbial growth pattern in 100 cases of corneal ulcers

\begin{tabular}{|l|l|l|l|}
\hline S.no. & culture & organism & $\%$ \\
\hline $\mathbf{1}$ & Positive & Staph. Aureus & $\mathbf{5 \%}$ \\
\hline $\mathbf{2}$ & Positive & Staph. Albus & $\mathbf{4 \%}$ \\
\hline $\mathbf{3}$ & Positive & Staph. Aureus + coagulase +ve B. xerosis & $\mathbf{1 \%}$ \\
\hline $\mathbf{4}$ & Positive & Staph. Aureus + coagulase +ve pneumococcai & $\mathbf{2 \%}$ \\
\hline $\mathbf{5}$ & Positive & candida & $\mathbf{4 \%}$ \\
\hline $\mathbf{6}$ & positive & aspergillus & $\mathbf{2 \%}$ \\
\hline & & & $\mathbf{1 8 \%}$ \\
\hline
\end{tabular}

Table2: Microbial growth pattern in 100 cases of corneal ulcers

\section{Treatment outcome}

This study included 100 cases of keratitis out of which In bacterial keratitis surgical intervention was required in $7.69 \%$, BCL in $9.6 \%$, Perforation occur in $19.2 \%$, whereas it healed in $59.61 \%$ and conjunctival hooding in $3.8 \%$. In fungal keratitis $27.77 \%, 13.8 \%, 41.6 \%$ and $36.11 \%$ respectively and in viral keratitis $11.11 \%$ require surgery, $55.55 \%$ healed, BCL in $11.11 \%, 22 \%$ pthisical in viral.

Table 3

Type of intervention (treatment given) and their outcome

\begin{tabular}{|l|l|l|l|l|l|}
\hline s.no. & Type of intervention & $\begin{array}{l}\text { Bacterial } \\
\text { keratitis }\end{array}$ & Fungal keratitis & Viral keratitis & mixed \\
\hline 1 & Surgery & $7.69 \%$ & $27.77 \%$ & $11.11 \%$ & - \\
\hline 2 & Bandage contact lens & $9.6 \%$ & $13.8 \%$ & $11.11 \%$ & - \\
\hline 3 & Healed & $59.6 \%$ & $36.11 \%$ & $55.55 \%$ & $100 \%$ \\
\hline 4 & Perforated & $19.2 \%$ & $41.6 \%$ & - & - \\
\hline 5 & Conjunctival hooding & $3.8 \%$ & - & - & - \\
\hline 6 & pthisical & - & - & - & $22.22 \%$ \\
\hline & TOTAL & $100 \%$ & $100 \%$ & $100 \%$ & $100 \%$ \\
\hline
\end{tabular}

\section{Discussion}

In many parts of the world, mainly in the developing countries, corneal ulceration is the major cause of blindness. As a result, corneal scarring is the second only to cataract as the most cause of visual disability in the world today (Whitcher et al 1997; Srinivasan et al 1997; Norina et al 2008; Upadhyaya et al 1991; Chirambo et al 1986; Brilliant LB et al, 1985).During analysis following data were deduced, $52 \%, 36 \%, 9 \%$ and $3 \%$ had bacterial, fungal, viral and mixed flora respectively It was noted that patients involved in agriculture activity or those suffering from trauma inflicted with vegetative material had more risk of developing microbial keratitis that is $44 \%$. Overall culture was positive in $12 \%$ of bacterial and mixed infection whereas only $6 \%$ of fungal keratitis clinically diagnosed, had culture positivity, whereas viral keratitis was diagnosed clinically only, who showed adequate responses to antiviral treatment. In bacterial keratitis surgical intervention was required in $7.69 \%$, BCL in $9.6 \%$, Perforation occur in $19.2 \%$, whereas it healed in $59.61 \%$ and conjunctival hooding in $3.8 \%$. In fungal keratitis $27.77 \%, 13.8 \%, 41.6 \%$ and $36.11 \%$ respectively and in viral keratitis $11.11 \%$ require surgery, $55.55 \%$ healed, BCL in $11.11 \%, 22 \%$ pthisical in viral. Study shows bacterial keratitis is more common than fungal \& viral with male predominance in younger age .trauma by vegetative material or injury is most common risk factor, final diagnosis based on risk factor, clinical feature, response to treatment .Viral keratitis diagnosed clinically. Bacterial keratitis has better prognosis than fungal and viral.

\section{Acknowledgement}

We are extremely thankful to Dr. R.K.JAIN, head of department of microbiology , N.S.C.B.Medical college and hospital, Jabalpur ( M.P.) for his contribution to the microbiological study of the samples.

\section{References}

[1]. Brilliant LB, Pokhrel RP, Grasset NC, Lepkowski JM, Kolstad A, Hawks W et al (1985). Epidemiology of blindness in Nepal. Bull WHO; 63: 375-86.

[2]. Basak SK, Basak S, Mohanta A et al (2005). Epidemiological and microbiological diagnosis of suppurative keratitis in Gangetic West Bengal, Eastern India. Indian J Ophthalm; 53:17-22.

[3]. Chirambo MC, Tielsch JM, Katz J et al (1986). Blindness and visual impairment in SouthernMalawi. Bull WHO; 64: 567-72.

[4]. Erie JC, Nevitt MP, Hodge DO, Ballard DJ (1993). Incidence of ulcerative keratitis in a defined population from 1950 through 1988. Arch Ophthal; 111:1665-71

[5]. Gopinathan U, Sharma S, Garg P, Rao GN et al (2009). Review of epidemiological features, microbiological diagnosis and treatment outcome of microbial keratitis, experience of over a decade. Indian J Ophthal; 57: 273-279.

[6]. Hagan M, Wright E, Newman M, Dolin P et al (1995). Causes of suppurative keratitis in Ghana. Br J Ophthal; 79:1024-28.

[7]. Lavaju P, Khanal B, Amatya R, Patel S (2009). Demographic pattern, clinical features and treatment outcome of patients with infective keratitis in the eastern region of Nepal. Nepjoph; 1(2):101-106. 
[8]. Norina TJ, Rainan S et al (2008). Microbial keratitis aetiological diagnosis and clinical features in patients admitted to Hospital University Sains Malaysia. Singapore Med J; 49(1): 67.

[9]. Srinivasan M, Christine A, Gonzales et al (1997). Epidemiology and aetiological diagnosis of corneal ulceration in Madurai, south India. Br J Ophthalm; 81: 965-971

[10]. Upadhyaya MP, Karmacharya PC, Koirala S, Tuladhar NR, Bryan LE, Smolin G et al (1991).

[11]. Epidemiologic characteristics, predisposing factors, and aetiologic diagnosis of corneal ulceration in Nepal. Am J Ophthalm; 111: 92-99.

[12]. Upadhyaya MP, Karmacharya PC, Koirala S, Shah DN, Shakya S, Shrestha JK et al ( 2001).

[13]. The Bhaktapur eye study: ocular trauma and antibiotic prophylaxis for prevention of corneal ulceration in Nepal. Br $\mathrm{J}$ Ophthalm; 85: 388-92.

[14]. Whitcher JP, Srinivasan M et al (1997). Cornealulceration in the developing world- a silent epidemic. Br J Ophthalm; 81: $622-623$.

[15]. Williams G, Billson F, Husain R, Howlader SA et al (1987). Microbiological diagnosis of suppurative keratitis in Bangladesh. Br J Ophthalm; 71:315-21. 